\title{
(2) OPEN ACCESS \\ What determines diagnostic resource consumption in emergency medicine: patients, physicians or context?
}

\author{
Wolf E Hautz (1) 1,2 Thomas C Sauter (1) 1,3 Stephanie C Hautz, ${ }^{1}$ \\ Juliane E Kämmer 우, ${ }^{4,5}$ Stefan K Schauber, ${ }^{2,6}$ Tanja Birrenbach, ${ }^{1}$ \\ Aristomenis K Exadaktylos, ${ }^{1}$ Stephanie Stock, ${ }^{7}$ Martin Müller (i) ${ }^{1,7}$
}

\section{Handling editor Richard Body \\ - Additional material is} published online only. To view please visit the journal online (http://dx.doi.org/10.1136/ emermed-2019-209022).

1 Department of Emergency Medicine, Inselspital Berne, Bern, Switzerland

${ }^{2}$ Center for Educational Measurement, University of Oslo, Oslo, Norway ${ }^{3}$ Medical Skills Lab, Charité Universitätsmedizin Berlin, Berlin, Germany

${ }^{4}$ Center for Adaptive Rationality Max-Planck-Institut fur Bildungsforschung, Berlin, Germany

${ }^{5}$ Institute of Health and Nursing Science, Charité Universitätsmedizin Berlin Berlin, Germany

${ }^{6}$ Faculty of Medicine, University of Oslo, Oslo, Norway ${ }^{7}$ Institute of Health Economics and Clinical Epidemiology, Cologne, University Hospital of Cologne, Cologne

\section{Correspondence to}

Dr Martin Müller, Department of Emergency Medicine, Inselspital Universitatsspital Bern, Bern 3010, Switzerland; martin.mueller2@insel.ch

Received 13 August 2019 Revised 15 April 2020 Accepted 22 April 2020 Published Online First 9 July 2020

Check for updates

(C) Author(s) (or their employer(s)) 2020. Re-use permitted under CC BY-NC. No commercial re-use. See rights and permissions. Published by BMJ.

To cite: Hautz WE, Sauter TC, Hautz SC, et al. Emerg Med J 2020:37:546-551.

\section{ABSTRACT}

Objectives A major cause for concern about increasing $E D$ visits is that ED care is expensive. Recent research suggests that ED resource consumption is affected by patients' health status, varies between physicians and is context dependent. The aim of this study is to determine the relative proportion of characteristics of the patient, the physician and the context that contribute to ED resource consumption.

Methods Data on patients, physicians and the context were obtained in a prospective observational cohort study of patients hospitalised to an internal medicine ward through the ED of the University Hospital Bern, Switzerland, between August and December 2015.

Diagnostic resource consumption in the ED was modelled through a multilevel mixed effects linear regression. Results In total, 473 eligible patients seen by one of 38 physicians were included in the study. Diagnostic resource consumption heavily depends on physicians' ratings of case difficulty $(p<0.001, z$-standardised regression coefficient: $147.5,95 \% \mathrm{Cl} 87.3$ to 207.7 ) and-less surprising —on patients' acuity $(\mathrm{p}<0.001$, $126.0,95 \% \mathrm{Cl} 65.5$ to 186.6 ). Neither the physician per se, nor their experience, the patients' chronic health status or the context seems to have a measurable impact (all $p>0.05$ ).

Conclusions Diagnostic resource consumption in the ED is heavily affected by physicians' situational confidence. Whether we should aim at altering physician confidence ultimately depends on its calibration with accuracy.

\section{INTRODUCTION}

A major cause for concern about increasing ED visits in most healthcare systems is that ED care is a relatively expensive form of healthcare. Several studies of ED patients triaged as non-urgent have investigated cost differences between patients seen by either the ED or by general practitioners (GP) situated adjunct to the ED. For example, a large randomised trial including 4684 patients found that GPs employed in a busy urban ED ordered fewer investigations, referred and admitted less often but prescribed more. ${ }^{1}$ Another trial comparing 4641 ED patients seen by either GPs or hospital physicians found care provided by GPs to be at least $35 \%$ cheaper. $^{2}$ Both trials found no differences in the clinical outcomes assessed, such as patient satisfaction, patients' general health status or unscheduled revisits over the next week. The reasons for the differences observed, however, remain largely

\section{Key messages}

What is already known on this subject

- Recent research suggests that ED resource consumption is affected by patients' health status, varies between physicians and is context dependent.

- The relative importance of these factors in the determination of resource consumption and thus the most promising targets for interventions are unknown.

\section{What this study adds}

- This cohort study found that diagnostic resource consumption in the ED is affected the most by physicians' situational confidence and by patients' acuity and not at all by their chronic state of health or ED workload.

- Whether we should aim at boosting physician confidence or their tolerance of uncertainty ultimately depends on that confidence calibration with accuracy.

unknown. Importantly, the GPs under investigation in the above trials did not have previous professional relationships to the patients seen adjunct to the ED.

Next to the relatively high costs of treating patients in the ED, the rising number of emergency visits further aggravates rising healthcare expenses. In the USA, EDs now provide nearly half of all medical care, a figure that has increased more than 44\% between 1996 and 2010. ${ }^{3}$ Across England's National Health System, more than 65000 people attended an ED every day in 2018 on average, a $7.5 \%$ increase over the last 5 years. ${ }^{4}$ In Australia, visits to the ED increased by $3.4 \%$ in $2017-2018$ compared with the previous year ${ }^{5}$ and by $2.4 \%$ in Canada over the same period. ${ }^{6}$

One frequent response to rising ED workload and the cost of care there is to question whether all visits constitute true emergencies or if at least some can be postponed to, for example, a timely (and cheaper) GP visit. ${ }^{1}$ While it has been shown that GPs who immediately attend to low-urgent ED patients within or adjunct to the ED seem to provide care of comparable quality more cost-effectively, ${ }^{12}$ it is unknown whether deferring patients to later visit an independent GP would result in similar outcomes.

Recent empirical evidence suggests that in fact, very few ED visits are unavoidable, ${ }^{7}$ and in addition, 
there is a paucity of GPs in many European countries. It thus seems unlikely that the demand for and the cost of ED care will decrease in the near future or can be substantially affected by strategies encouraging presentation elsewhere. Consequently, how the available ED resources are used becomes a crucial question to maintain operational availability of emergency care. It is thus important to understand the factors that determine ED resource consumption as well as the comparative magnitude of their effects.

In a fully rational world, one would expect ED resource consumption to result from patients' acuity and their chronic conditions only. Indeed, ED resource usage is highest in both very young infants ${ }^{8}$ and the elderly. ${ }^{9}$ Not surprisingly, patients in more urgent triage categories also take up more ED resources than healthier patients ${ }^{10}$ and some conditions, such as intoxications, require comparatively more resources than others. ${ }^{11}$

However, the use of diagnostic resources also varies between physicians, even for identical patients. Lawton and colleagues recently demonstrated, in a vignette study, that less experienced emergency physicians employ more resource-intensive patient management strategies than their more experienced colleagues do. ${ }^{12}$ Similarly, less experienced residents ordered up to five times as many diagnostic tests per patient than their more experienced peers in a large retrospective analysis of diagnostic test ordering behaviour in internal medicine. ${ }^{13}$

One potential driver for these findings may be physicians' (un)certainty in their diagnoses. GPs respond to uncertainty by ordering more diagnostic tests ${ }^{14}$ and those with lower tolerance of uncertainty generate higher costs. ${ }^{15}$ Arguably, gathering more information in a situation where one is uncertain seems reasonable and should be encouraged in the best interest of patients. ${ }^{1617}$ However, a physician's general intolerance of uncertainty could lead to overly defensive medicine and should thus be subjected to (educational) interventions. Because of these differences in their consequences, physicians' situational uncertainty (a state) and their tolerance of uncertainty in general (a trait) should be carefully distinguished. ${ }^{17}$

Next to the patients and physicians' characteristics, contextual factors such as workload, crowding and waiting times (time to first ED physician contact) also affect ED resources. For example, in a retrospective analysis of 180000 patients in a large US ED, Woodworth and Holmes found that longer waiting times are associated with higher overall costs of care; this effect was most pronounced in the sickest but disappeared for healthier patients, suggesting an interaction effect between waiting time and triage level on the determination of resource usage. ${ }^{18}$ Crowding further affects resources in at least three known ways. ${ }^{19}$ It leads to longer ED stays and consequently longer waiting times for other patients, ${ }^{20}$ it results in longer length of hospital stays, ${ }^{21}$ increasing resource consumption of processes downstream from the ED, and it results in the conduct of unnecessary procedures in the ED. ${ }^{19}$

In summary, characteristics of the patient, the physician and the context all seem to affect ED resource consumption. However, the relative magnitude of their effects-and thus the most promising intervention goals-remain unknown. Furthermore, it is not clear how characteristics of the patient, the physician and the context interact in determining ED resource use. The aim of this study therefore is to determine the characteristics of the patient, the physician and the context that contribute to ED resource consumption and their relative importance when compared with each other.

\section{METHODS}

\section{Study design and cohort description}

This study is a secondary analysis of a data set obtained during the $\mathrm{cDx}$ study (change in diagnosis study), a prospective observational cohort study of all ED patients who were hospitalised to a medical ward between 15 August and 7 December 2015. The primary analysis investigated whether diagnostic error in the ED could be predicted by case or context variables available in the ED and whether such error affects outcome. ${ }^{22}$ The ED under investigation is a level 1 trauma centre, part of the University Hospital of Bern, Switzerland, and treats over 48000 patients annually. All patients admitted to a medical ward from the ED during the study period were eligible for study inclusion.

\section{Patient and public involvement}

No patients were involved in the design and conduct of this study. We plan to disseminate the findings of this study among patients in scientific presentations to the general public at the University of Bern.

\section{Data collection and extraction}

During the study, data were collected from different sources and on different occasions.

First, professional experience was collected from each physician working in the ED before inclusion of the first patient.

Then, emergency physicians filled in a questionnaire directly after admission of each patient to a medical ward, providing their evaluations of the case (confidence in their diagnosis, their familiarity with similar cases and the case's difficulty) and of the context (tiredness and perceived workload) on 5-point Likert scales. Physicians received US $\$ 10$ for each completed questionnaire.

Patients' demographic and medical data (age, sex, triage, type of admission, first vital signs in the ED and diagnoses) were extracted from the ED's electronic health record (E-Care, ED 2.1.3.0, Turnhout, Belgium). Case severity index (see section Patient characteristics, chronic, below) was obtained from the administrative database (OpenText Suite for SAP Solutions, OpenText, Waterloo, Canada).

Last, procedural codes, such as for a CT scan, physicians' examination or laboratory tests that were routinely entered into the administrative patients' database by the person who provided the procedure, were extracted. This database converts all procedural codes into so-called 'tax points', a national medical currency defined by Swiss healthcare law (TARMED Suisse, TARMED, 01.06.2012). In November 2019, 1 tax point roughly equated to $0.86 \mathrm{CHF}$ (or $€ 0.78$ or US\$0.87). We used tax points as unit of analysis because they reflect the medical effort required for any diagnostic or therapeutic measure, while their conversion to a currency changes on at least annual basis and takes cost developments, regulatory decisions, reimbursement differences between Swiss cantons and case complexity into account. Tax points for physician's effort, radiology resources and laboratory resources were summed up to obtain the total diagnostic ED resources per patient, which is the dependent variable of this study.

\section{Eligibility criteria}

All patients admitted to a medical ward from the ED during the study period were eligible for study inclusion. Patients with missing data were excluded from the analysis. If no questionnaire of the resident in charge was available, but a questionnaire of the consultant in charge, the questionnaire of the consultant in charge was sufficient for study inclusion. If multiple residents 


\begin{tabular}{|c|c|c|}
\hline \multirow{2}{*}{$\begin{array}{c}\text { Patient's condition (chronic) } \\
\text { Age (years), (med (IQR)) }\end{array}$} & \multicolumn{2}{|c|}{ Total $(n=473)$} \\
\hline & 70.5 & $(56.6-80.5)$ \\
\hline Sex (male), (n (\%)) & 261 & $(55.2)$ \\
\hline Case severity index (points), (med (IQR)) & 0.9 & $(0.6-1.3)$ \\
\hline \multicolumn{3}{|l|}{ Patient's condition (acuity) } \\
\hline \multicolumn{3}{|l|}{ Triage category, (n (\%)) } \\
\hline Highly urgent & 15 & $(3.2)$ \\
\hline Urgent & 224 & (47.4) \\
\hline Semiurgent & 210 & $(44.4)$ \\
\hline Non-urgent & 24 & $(5.1)$ \\
\hline Resuscitation bay, (n (\%)) & 47 & (9.9) \\
\hline Systolic BP <90 mm Hg, (n (\%)) & 17 & (3.6) \\
\hline HR deviation, $>110$ or $<50$ bpm, (n (\%)) & 2 & $(0.4)$ \\
\hline Oxygen saturation $<90 \%$, (n (\%)) & 19 & $(4.0)$ \\
\hline \multicolumn{3}{|l|}{ Physician characteristics, (n (\%)) } \\
\hline Highly experienced (>10 years) & 95 & (20.1) \\
\hline Experienced (>5-10 years) & 146 & $(30.9)$ \\
\hline Limited experience (>2-5 years) & 219 & $(46.3)$ \\
\hline Unexperienced ( $\leq 2$ years) & 13 & (2.7) \\
\hline \multicolumn{3}{|l|}{ Context characteristics } \\
\hline NEDOCS mean, (med (IQR)) & 49.5 & $(33.8-68.0)$ \\
\hline Tiredness (1: awake, 5: tired), (med (IQR)) & 3.0 & $(2-3)$ \\
\hline Workload (1: low, 5: high), (med (IQR)) & 3.0 & $(3-4)$ \\
\hline Night admission, (n (\%)) & 138 & $(29.2)$ \\
\hline Weekend consultation, (n (\%)) & 111 & (23.5) \\
\hline \multicolumn{3}{|l|}{ Subjective case difficulty } \\
\hline Uncertainty (1: low, 5: high), (med (IQR)) & 2.0 & $(1-3)$ \\
\hline Difficulty (1: low, 5: high), (med (IQR)) & 2.0 & $(2-3)$ \\
\hline Unfamiliarity (1: familiar, 5: unfamiliar), (med (IQR)) & 2.0 & $(1-3)$ \\
\hline \multicolumn{3}{|l|}{ Outcome } \\
\hline Total diagnostic ED resources, (med (IQR)) & 1172 & $(852-1645)$ \\
\hline
\end{tabular}

med, median; NEDOCS, National Emergency Department Overcrowding Score.

were involved in the treatment of a patient, the questionnaire of the physician who treated the patient at the ED for the longest time was considered for analysis.

\section{Predictor variables of diagnostic ED resource usage}

Variables were coded so that an increase of the variable would lead to an increase of the total resource consumption if there was an association. All continuous variables were z-standardised (transformed so that their mean was 0 and their SD was 1) to allow for a direct comparison. Next, we grouped variables to meaningful clusters (detailed below), representing the constructs subjective case difficulty, context characteristics, physician experience, patient's condition (chronic) and patient's condition (acuity).

\section{Subjective case difficulty}

Physician's situational uncertainty in their diagnosis (the higher, the less certain), perceived case difficulty (the higher, the more difficult) and unfamiliarity (the higher, the less familiar) were grouped into the cluster subjective case difficulty.

\section{Context characteristics}

Five variables were used to describe the context of each consultation: physicians' rating of their tiredness and their subjective workload (obtained from the questionnaire), the mean National Emergency Department Overcrowding Score during the patients' stay in the ED, as well as two binary variables indicating night-time admission (19:00-06:59) and type of day (workday/ no workday).

\section{Physician experience}

Physicians were described by their work experience recorded as highly experienced ( $>10$ years), experienced ( $>5-10$ years), with limited experience $(>2-5$ years) and unexperienced $(\leq 2$ years).

\section{Patient characteristics, acuity}

Variables characterising the patient's acuity condition were triage scale, use of a resuscitation bay and deviations from normal BP, HR and oxygen saturation. The deviation limits were defined based on cut-offs that were associated with poor outcome on ED presentation in the literature: an oxygen saturation below 90\%, a systolic BP of less than $90 \mathrm{~mm} \mathrm{Hg}$ and an HR outside the range of 50-110 bpm.

\section{Patient characteristics, chronic}

The patients' chronic condition is characterised by patient's age and sex and the case severity index. The case severity is a positive number assigned to each hospitalised patient for billing purposes; its magnitude is based on comorbidities and diagnosisrelated group.

\section{Outcome}

The total emergency diagnostic resources of a patient were defined as the sum of all radiological, laboratory and physician's tax points during the patients' stay at the ED.

\section{Statistical methods}

Stata V.13.1 (StataCorp, College Station, Texas, USA) was used to conduct statistical analysis. The distribution of a variable was described by total and relative numbers for categorical variables. Continuous variables were described with the median and IQR.

Univariable linear regression analysis was used to predict total diagnostic resource consumption out of each variable separately.

Because variables in each cluster were positively associated/ correlated with each other $\left(\chi^{2}\right.$ test, Wilcoxon rank-sum test or Spearman rank correlation, see online supplement 2), in each of the five clusters, case difficulty, context characteristics, physician experience (years of education), patient's condition (chronic) and patient's condition (acuity), one composite score was constructed for each cluster. ${ }^{23}$ The $\mathrm{z}$-transformed variables within each cluster were averaged per patient. The resulting composite was again z-transformed to allow for comparability between clusters.

A multilevel mixed effects linear regression model using Stata's mixed command was calculated to model the total ED resource consumption based on the cluster composites with the physician identification number as a random intercept to account for physicians treating more than one patient. Because all prediction variables were $\mathrm{z}$-transformed, the coefficients can be compared to evaluate the impact of each cluster on the EDs diagnostic resource consumption. For sensitivity analysis, two different models were calculated. First, a multilevel mixed effects linear regression model was calculated based on untransformed unpooled potential predictor variables (ie, not from cluster composite scores). Second, we calculated the principal component in each cluster using principal component analysis (Stata's PCA command) and performed a multilevel mixed effects linear regression model (physician identification number 


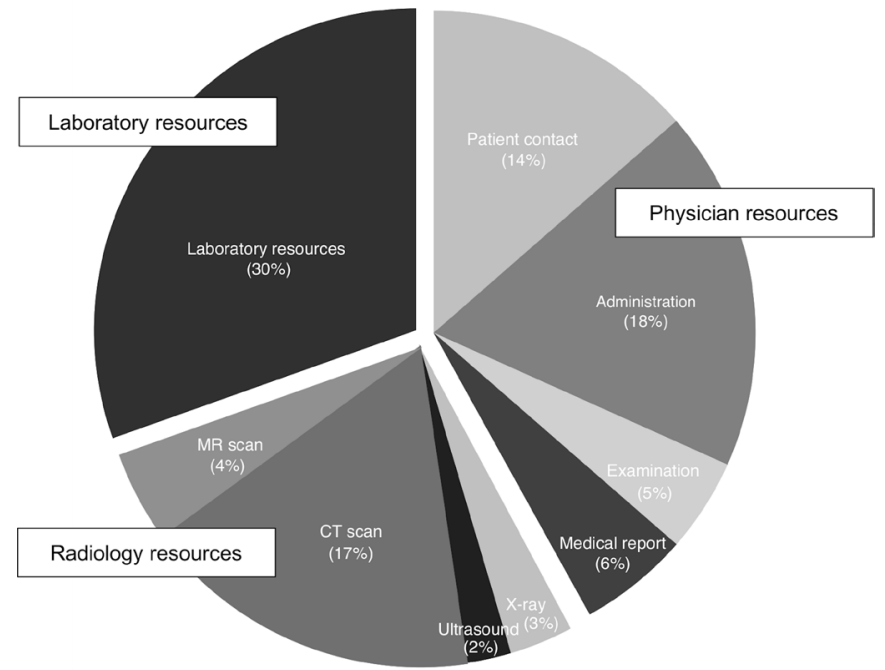

Figure 1 Distribution of the total emergency diagnostic resource use $(n=473)$.

as the random intercept model) with the z-transformed principal component variables in each cluster.

\section{RESULTS}

Out of 755 eligible medical hospitalisations, 495 (65.6\%) questionnaires were returned from physicians. Of these, $4.4 \%$ $(n=22)$ had to be excluded because of missing or incomplete data in any of the study predictors, resulting in a total of 473 consultations for analysis.

These patients were treated by 38 different physicians, with a median professional experience of 5 years (IQR: $3-7$ ). The

\begin{tabular}{|c|c|c|c|}
\hline Total diagnostic resources & Coefficient & $95 \% \mathrm{Cl}$ & $P$ value \\
\hline \multicolumn{4}{|l|}{ Patient's condition (chronic) } \\
\hline Age, older & 32.4 & (-30.8 to 95.5$)$ & 0.315 \\
\hline Sex, male & 6.2 & ( -57 to 69.5$)$ & 0.846 \\
\hline Case severity index, more severe & 85.7 & (23 to 148.5 ) & 0.008 \\
\hline \multicolumn{4}{|l|}{ Patient's condition (acuity) } \\
\hline Triage category, more urgent & 186.8 & (125.9 to 247.8$)$ & $<0.001$ \\
\hline Resuscitation bay, yes & 135.6 & (73.5 to 197.6$)$ & $<0.001$ \\
\hline Systolic BP $<90 \mathrm{~mm} \mathrm{Hg}$, yes & 70 & (7.1 to 132.9 ) & 0.029 \\
\hline HR deviation, $>110$ or $<50 \mathrm{bpm}$, yes & -36.4 & $(-99.5$ to 26.7$)$ & 0.258 \\
\hline Oxygen saturation $<90 \%$, yes & 8.8 & $(-54.4$ to 72$)$ & 0.785 \\
\hline \multicolumn{4}{|l|}{ Physician's characteristics } \\
\hline Experienced, less & 40.5 & $(-22.6$ to 103.6$)$ & 0.208 \\
\hline \multicolumn{4}{|l|}{ Context characteristics } \\
\hline Tiredness, more & 20.1 & (-43.1 to 83.2$)$ & 0.533 \\
\hline $\begin{array}{l}\text { Workload NEDOCS (objective), } \\
\text { higher }\end{array}$ & -9.7 & $(-72.9$ to 53.5$)$ & 0.763 \\
\hline Workload (subjective), higher & 28.3 & (-34.8 to 91.5$)$ & 0.378 \\
\hline Night admission, yes & -19.4 & (-82.6 to 43.8$)$ & 0.546 \\
\hline Weekend consultation, no & -17.8 & ( -81 to 45.4$)$ & 0.581 \\
\hline \multicolumn{4}{|l|}{ Subjective case difficulty } \\
\hline Insecurity, higher & 101.9 & (39.4 to 164.5 ) & 0.001 \\
\hline Difficulty, higher & 175.5 & (114.3 to 236.7$)$ & $<0.001$ \\
\hline Familiarity, less familiar & 126.7 & (64.5 to 188.9 ) & $<0.001$ \\
\hline
\end{tabular}

NEDOCS, National Emergency Department Overcrowding Score.
Table 3 Multilevel mixed effects linear regression model (physician identification number as the random intercept model) to predict the total ED diagnostic resource use out of the pooled variables for physicians and patients' characteristics (z-transformed variables) $(\mathrm{n}=473)$

\begin{tabular}{|c|c|c|c|}
\hline Total ED diagnostic resources & Coefficient & $95 \% \mathrm{Cl}$ & $P$ value \\
\hline $\begin{array}{l}\text { Patient's condition (chronic), older/ } \\
\text { more comorbidities }\end{array}$ & 51.0 & $(-9.4$ to 111.4$)$ & 0.098 \\
\hline $\begin{array}{l}\text { Patient's condition (acuity), more } \\
\text { urgent }\end{array}$ & 126.0 & (65.5 to 186.6$)$ & $<0.001$ \\
\hline Physician's experience, less & 27.9 & $(-32.7$ to 88.5$)$ & 0.367 \\
\hline Context characteristics, worse & -3.4 & $(-63.7$ to 57.0$)$ & 0.913 \\
\hline $\begin{array}{l}\text { Subjective case difficulty, more } \\
\text { difficult }\end{array}$ & 147.5 & (87.3 to 207.7 ) & $<0.001$ \\
\hline Constant & 1333.9 & (1273.8 to 1393.9 ) & $<0.001$ \\
\hline
\end{tabular}

median number of included patients seen per physician during the study period was 6 (IQR 4-10). The consultation characteristics are detailed in table 1 and online supplement 1.

The median total ED resource use was 1172 (IQR: 852-1645) tax points. Physicians' effort made up for $43.6 \%$ of the total resource use followed by laboratory (29.7\%) and radiological resources (26.7\%), see figure 1 .

In univariable analysis, the case severity index $(p=0.008)$, the triage category $(p<0.001)$, resuscitation bay use $(p<0.001)$, a systolic BP below $90 \mathrm{~mm} \mathrm{Hg}(\mathrm{p}=0.029)$, as well the subjective case difficulty variables insecurity, difficulty and familiarity (all $\mathrm{p} \leq 0.001$ ) showed a significant positive association with the total ED resource use (see table 2).

The multilevel mixed effects linear regression model revealed a significant association of total ED resource consumption with the composite scores for subjective case difficulty and patient's acuity, but not for context, physician experience or patient's chronic characteristics, with the highest coefficient for subjective case difficulty, see table 3 . The intraclass correlation coefficient for the mixed effects model with physician identification number as the random effect was 0.006 (95\% CI 0.000 to 0.870 ), suggesting that diagnostic resource consumption is independent of the physician per se.

The sensitivity analysis considering all unpooled, untransformed predictor variables showed a significant association with case severity index $(\mathrm{p}=0.01)$, more urgent triage category $(p<0.001)$, resuscitation bay $(p=0.015)$ and difficulty $(\mathrm{p}<0.001)$, see online supplement 3 . Using principal component analysis to obtain a variable for each cluster, the final model confirmed significant associations with the principal component for subjective case difficulty and patient's acuity with coefficients of a magnitude comparable to the primary analysis, see online supplement 4 .

\section{DISCUSSION}

Previous research suggests that characteristics of the patient, the physician and the context all determine how much resources will be invested in the diagnostic process. ${ }^{8-10} 12-152425$ To the best of our knowledge, our analysis is the first to assess the relative importance of each of these factors in combination and to thus allow for the identification of the most promising targets for interventions. We find that diagnostic resource consumption in the ED is to the largest degree dependent on physicians' ratings of case difficulty (ie, their perceived situational level of uncertainty, familiarity and difficulty), followed by the patients' acuity with about a $20 \%$ difference. Notably, resource consumption 
seems neither to be affected by physician experience, nor are some physicians generally investing more resources than others (although this finding is limited by the low number of patients per physician in our data set). Likewise, contextual factors such as physicians' workload or fatigue or the patients' chronic conditions seem to have no measurable impact on ED resource consumption.

These results have several implications. First, it is unlikely that the preferred use of experienced physicians will reduce the consumption of diagnostic resources in EDs. Similarly, reducing the workload per ED physician is unlikely to have any impact on diagnostic resources per case, although there are plenty of other reasons to limit physician workload in the ED. ${ }^{26}$ Second, while the acuity of the patient per se is the very justification for the existence of emergency medicine, the subjective assessment of the difficulty of a case by the attending physician could be a goal of possible interventions. It remains an open question whether it should be. ${ }^{17}$

On the one hand, the confidence of physicians in their diagnostic ability overall is essentially independent of their diagnostic performance but rather an expression of their self-conception. ${ }^{27}$ Some have thus argued that medicine and medical education alike should strive to instil tolerance of uncertainty to a certain degree in its trainees and abandon our 'stubborn quest for diagnostic certainty ${ }^{28}$ in a fundamentally uncertain environment. ${ }^{28}$ Recent experimental evidence suggests that indeed, those emergency physicians with higher general tolerance of uncertainty adopt less resource-intensive patient management strategies. ${ }^{12}$

On the other hand, physicians' situational confidence (sometimes termed self-monitoring) is known to correlate well with the accuracy of their diagnosis in a concrete case. ${ }^{27}$ If at all distorted, then physicians seem to be rather overconfident about their diagnostic performance. Consequently, one could argue that physicians who respond to their situational uncertainty by investing more resources in further diagnostic tests are actually acting in the best interest of their patients. If situational uncertainty is actually an expression of an increased risk of misdiagnosis (as suggested by various studies (eg, reference 27)), then it would be desirable, and even necessary, for the insecure physician to use more diagnostic means to follow-up on his or her metacognitive judgement of feeling uncertain. ${ }^{16}$

These arguments ultimately raise the question of whether the situational uncertainty of a physician is appropriate or not. ${ }^{17}$ If uncertainty results from incomplete, unreliable or contradictory information and is associated with misdiagnosis, then uncertainty is a useful indication that the use of more resources would be appropriate. However, if uncertainty results from a lack of experience with similar cases, the misinterpretation of information or simply a lack of knowledge, then uncertainty and its tolerance would certainly be a good interventional target. Consequently, developing methods to help physicians identify the sources of their uncertainty (or use the right cues to inform their metacognitive judgement of certainty) could prove a fruitful avenue for further research. One rather accessible source of better calibration of confidence with accuracy could simply be collaboration with a colleague, a behaviour that frequently occurs in emergency rooms and educational environments anyway.

The interpretation of our findings warrants consideration of several limitations. First, this study reports findings from a single centre only. Second, we only included patients hospitalised to an internal medicine ward, potentially limiting the transferability of our findings to other patient populations, especially those patients discharged from the ED. This limitation is however accompanied by one of the key strengths of the study, because our inclusion criteria result in a homogenous population where the effect of outliers in resource consumption, such as patients admitted for social or palliative reasons on the one hand or patients under resuscitation or suffering from major trauma on the other, is limited. Third, the large constant in multilevel liner mixed regression (table 3) suggests that all predictor variables assessed in our study jointly only predict a small part of resource consumption overall. Fourth, a response bias cannot be excluded (response rate: 65.6\%), although whether or not physicians filled in a questionnaire was independent of the patients' acuity, gender, or mode of presentation, weekday, daytime or ED crowding in a sensitivity analysis. Furthermore, in $53.7 \%$ of the cases our analysis is based on the questionnaire by the consultant, not the resident in charge of that patient. We did not find any systematic variation between questionnaires filled in by either group, but it is nevertheless possible that consultants responded somehow differently than residents. Last, it should be acknowledged that technically, our results demonstrate an association of physicians' certainty and patient acuity with diagnostic resource consumption, not a causal relationship.

\section{CONCLUSION}

Diagnostic resource consumption in the emergency room is mostly affected by physicians' situational confidence and - to a lesser degree - patient acuity. Neither the physician per se, nor the context or the patients' chronic conditions explain resource consumption. Whether we should aim at altering physician's perceived confidence ultimately depends on its source and its predictive value for accuracy.

Contributors All authors contributed to the conception of the study, analysis and interpretation of the results and the final approval of the manuscript. Study design: MM, WEH, SS. Data analysis: MM, SKS. Drafting the manuscript: WEH, MM. Critical revision of the manuscript for intellectual content: WEH, TCS, SCH, JEK, SKS, TB, AE, SS, MM.

Funding MM was funded by the Bangarter Foundation and the Swiss Academy of Medical Sciences through the 'Young Talents in Clinical Research' grant (TCR 14/17) as well as through a CTU grant of Inselgruppe.

Competing interests WEH received speaker honorariums from the AO Foundation in Zurich and research funding from Mundipharma Medical Basel. TCS has received research grants or lecture fees from Bayer, Boehringer Ingelheim and Daiichi-Sankyo and the Gottfried and Julia Bangerter-Rhyner Foundation.

Patient and public involvement Patients and/or the public were not involved in the design, or conduct, or reporting, or dissemination plans of this research.

Patient consent for publication Not required.

Ethics approval The CDx study was classified as a quality evaluation study by the local institutional review board (KEK 197/15) and the need for informed consent was waived.

Provenance and peer review Not commissioned; externally peer reviewed.

Data availability statement Data are available upon reasonable request. The data used to support the findings of this study are available from the corresponding author upon request for researchers eligible to work with codified health data under Swiss legislation. Eligibility will be determined by the ethics committee.

Open access This is an open access article distributed in accordance with the Creative Commons Attribution Non Commercial (CC BY-NC 4.0) license, which permits others to distribute, remix, adapt, build upon this work non-commercially, and license their derivative works on different terms, provided the original work is properly cited, appropriate credit is given, any changes made indicated, and the use is non-commercial. See: http://creativecommons.org/licenses/by-nc/4.0/.

\section{ORCID iDs}

Wolf E Hautz http://orcid.org/0000-0002-2445-984X

Thomas C Sauter http://orcid.org/0000-0002-6646-5789

Juliane E Kämmer http://orcid.org/0000-0001-6042-8453

Martin Müller http://orcid.org/0000-0003-4067-7174 


\section{REFERENCES}

1 Murphy AW, Bury G, Plunkett PK, et al. Randomised controlled trial of general practitioner versus usual medical care in an urban accident and emergency department: process, outcome, and comparative cost. BMJ 1996;312:1135-42.

2 Dale J, Lang H, Roberts JA, et al. Cost effectiveness of treating primary care patients in accident and emergency: a comparison between general practitioners, senior house officers, and registrars. BMJ 1996;312:1340-4.

3 Marcozzi D, Carr B, Liferidge A, et al. Trends in the contribution of emergency departments to the provision of hospital-associated health care in the USA. Int J Health Serv 2018;48:267-88.

4 Baker C. Nhs key statistics: England, October 2018. house of commons library, 2018. Available: https://researchbriefings.files.parliament.uk/documents/CBP-7281/ cbp07281-oct18.pdf

5 Australian Institute of Health and Welfare. Emergency department care 2017-18: Australian hospital statistics. Canberra: AlHW, 2018.

6 Canadian Institute for Health Information. NACRS emergency department (ED) visits: volumes and median length of stay by triage level, visit disposition, and main problem. Available: https://www.cihi.ca/en/nacrs-emergency-department-ed-visitsvolumes-and-median-length-of-stay-by-triage-level-visit

7 Morris T, Mason SM, Moulton C, et al. Calculating the proportion of avoidable attendances at UK emergency departments: analysis of the Royal College of emergency medicine's sentinel site survey data. Emerg Med J 2018;35:114-9.

8 Leigh S, Grant A, Murray N, et al. The cost of diagnostic uncertainty: a prospective economic analysis of febrile children attending an NHS emergency department. BMC Med 2019;17:48.

9 Latham LP, Ackroyd-Stolarz S. Emergency department utilization by older adults: a descriptive study. Can Geriatr J 2014;17:118-25.

10 Hocker M, Gerardo C, Theiling J, et al. NHAMCS validation of emergency severity index as an indicator of emergency department resource utilization. West J Emerg Med 1996;19:855-62.

11 Klenk L, von Rütte C, Henssler JF, et al. Resource consumption of multisubstance users in the emergency room: A neglected patient group. PLoS One 2019; 14:e0223118.

12 Lawton R, Robinson O, Harrison R, et al. Are more experienced clinicians better able to tolerate uncertainty and manage risks? A vignette study of doctors in three NHS emergency departments in England. BMJ Qual Saf 2019;28:382-8.
13 Geleris JD, Shih G, Logio L. Analysis of diagnostic test ordering habits among internal medicine residents. JAMA Intern Med 2018;178:178.

14 Tsiga E, Panagopoulou E. Risking your health while saving lives? In: Milestones and Transitions-Maintaining the Balance. London, 2014.

15 Alam R, Cheraghi-Sohi S, Panagioti M, et al. Managing diagnostic uncertainty in primary care: a systematic critical review. BMC Fam Pract 2017;18:79.

16 Hautz WE. When I say... diagnostic error. Med Educ 2018;52:896-7.

17 Zwaan L, Hautz WE. Bridging the gap between uncertainty, confidence and diagnostic accuracy: calibration is key. BMJ Qual Saf 2019;28:352-5.

18 Woodworth L, Holmes JF. Just a minute: the effect of emergency department wait time on the cost of care. Econ Inq 2020;58:698-716.

19 Hoot NR, Aronsky D. Systematic review of emergency department crowding: causes, effects, and solutions. Ann Emerg Med 2008;52:126-36.

20 Bayley MD, Schwartz JS, Shofer FS, et al. The financial burden of emergency department congestion and hospital crowding for chest pain patients awaiting admission. Ann Emerg Med 2005;45:110-7.

21 Krochmal P, Riley TA. Increased health care costs associated with ED overcrowding. Am J Emerg Med 1994;12:265-6.

22 Hautz WE, Kämmer JE, Hautz SC, et al. Diagnostic error increases mortality and length of hospital stay in patients presenting through the emergency room. Scand J Trauma Resusc Emerg Med 2019;27:54.

23 Song M-K, Lin F-C, Ward SE, et al. Composite variables: when and how. Nurs Res 2013;62:45-9.

24 Traub SJ, Saghafian S, Buras MR, et al. Resource utilization in emergency department patients with known or suspected poisoning. J Med Toxicol 2017;13:238-44.

25 Allison JJ, Kiefe $\mathrm{Cl}$, Cook EF, et al. The association of physician attitudes about uncertainty and risk taking with resource use in a Medicare HMO. Med Decis Making 1998;18:320-9.

26 Westbrook JI, Raban MZ, Walter SR, et al. Task errors by emergency physicians are associated with interruptions, multitasking, fatigue and working memory capacity: a prospective, direct observation study. BMJ Qual Saf 2018;27:655-63.

27 Hautz WE, Schubert S, Schauber SK, et al. Accuracy of self-monitoring: does experience, ability or case difficulty matter? Med Educ 2019;53:735-44.

28 Kassirer JP. Our stubborn quest for diagnostic certainty. N Engl J Med Overseas Ed 1989:320:1489-91. 